\title{
Materialismo histórico-dialético como fundamento da psicologia histórico-cultural: método e metodologia de pesquisa
}

\author{
Review Historical and dialectical materialism as the foundation of \\ cultural-historical psychology: method and research methodology
}

\section{Reseña El materialismo histórico y dialéctico como la fundación de La psicología histórico-cultural: método y metodología de la investigación}

\author{
Eduardo Moura da Costa \\ Universidade Estadual Paulista - Assis - SP - Brasil
}

\begin{abstract}
Tuleski, S. C.; Chaves, M. \& Leite, H. A. (Orgs.) (2015). Materialismo histórico-dialético como fundamento da psicologia histórico-cultural: método e metodologia de pesquisa. Maringá: Eduem, 194 p.
\end{abstract}

Vigotski (2010) nos ensinou que uma das principais tarefas no estudo do desenvolvimento humano é entender como o meio se tornava fonte de desenvolvimento. $\mathrm{O}$ autor buscou compreender o desenvolvimento histórico-cultural do psiquismo humano de forma a superar a tradição empirista, caracterizada pela análise quantitativa, descritiva e biologizante dos fenômenos. É justamente essa perspectiva que orienta os textos aqui apresentados. Os autores dos textos reunidos nesta coletânea apresentaram tanto a metodologia do conhecimento quanto exemplos de investigações que partem da relação dialética entre o sujeito e a sociedade. Desta maneira, esta obra é altamente recomendada para psicólogos e educadores comprometidos em entender os impactos individuais da sociedade capitalista atual.

A primeira parte, intitulada "Pensando o método que conduz a análise" inicia-se com o texto "Do método ou de como pensar o pensamento", escrito por Lizia Helena Nagel. A autora destaca que o método marxista não pode ser pensando como uma sequência lógica de regras e leis da dialética ou da história. Diferentemente da ideologia pós-moderna que diz que o conhecimento é um produto individual e que não haveria formas de se conhecer a realidade para transformá-la, a autora destaca que o método materialista histórico está intimamente conectado às praticas sociais, ao seu fundante, o trabalho. Portanto, antes de aplicar certas regras epistemológicas devemos primeiro nos perguntar o que a realidade é para essa epistemologia. Para Marx não existiria uma essência humana, mas seria o próprio homem, através do trabalho, que produz e cria necessidades ao longo do movimento histórico. Nesse sentido, segundo a autora, o conhecimento para Marx não se desloca da sua reprodução social, pois todo pensamento está conectado às práticas humanas, que são essencialmente contraditórias, nunca individuais.

O segundo texto intitula-se "As aparências enganam: divergências entre o materialismo histórico dialético e as abordagens qualitativas de pesquisa", escrito por Lígia Márcia Martins. Seu objetivo é demonstrar que "o marxismo dispensa a adoção das abordagens qualitativas na legitimação da cientificidade de seus métodos de investigação" (p. 29). A epistemologia materialista histórico-dialética seria suficiente para a atividade científica. A metodologia qualitativa parte da 
lógica formal, excludente, diferentemente da lógica dialética que não exclui, mas incorpora por superação, chegando a "identidade dos contrários". Além disso, a metodologia qualitativa fetichiza a realidade empírica imediata, perdendo de vista os fundamentos essenciais da realidade humana. Para o materialismo histórico-dialético a essência da realidade não está explícita imediatamente, mas necessita ser compreendida pelo pensamento teórico, abstrato, através da apreensão do fenômeno em suas múltiplas mediações histórico-concretas.

Achilles Delari Junior fecha a primeira parte do livro com o texto intitulado "Questões de método em Vigotski: busca da verdade e caminhos da cognição". Conforme o autor, a questão da metodologia, para a psicologia russo-soviética, não se restringe aos problemas da pesquisa empírica, mas referem-se também aos estudos das questões teóricas envolvidas na investigação dos fenômenos psicológicos. O autor então apresenta quatro categorias metodológicas (meta-teóricas) gerais que podem ser extraídas dos escritos de Vigotski. Por fim são apresentadas as principais inovações teórico-metodológicas de Vigotski: a) Método instrumental; b) Método genético-experimental; c) O estudo da consciência e a análise sêmica ou semântica; d) $O$ método de análise por unidades.

A segunda parte da obra, "Caminhos para as aplicações do método em pesquisa", inicia-se com o texto "A educação de jovens e adultos sob os fundamentos do método materialista histórico-dialético: a formação do trabalhador precariamente escolarizado para além das aparências", da autoria de Graziela Lucchesi Rosa da Silva. O foco do texto é compreender como se dá a relação entre as condições precárias de aprendizagem de jovens e adultos dentro de uma sociedade em crise estrutural. Analisa-se a desigualdade social tendo como origem a luta de classes na sociedade capitalista e a consequente precarização da formação humana. A autora investigou como se dá a relação entre trabalho, em seu sentido ontológico, e a alienação na origem da precarização da formação humana. Os jovens e adultos precariamente escolarizados não são produzidos por uma escola de baixa qualidade, mas são o resultado de uma sociedade que produz alienação. Conclui-seque é fundamental conhecer as leis que regem o mundo do trabalho para se criar possibilidades reais de enfrentamento ao fracasso da escolarização de jovens e adultos.

Na sequência, no capítulo quinto, tem-se o texto "Vida e obra de Elkonin: relato de uma pesquisa biográfica sustentada pelos princípios do materialismo histórico-dialético", da autoria de Lucinéia Maria Lazaretti. A pesquisa biográfica do psicólogo soviético buscou articular seu tempo com sua produção teórica no campo do desenvolvimento humano em sua relação com a realidade circundante. A principal preocupação do autor foi articular sua produção teórica com a prática educativa. Seus principais objetos de pesquisa foram temas relacionados à infância, tais como o desenvolvimento infantil, desenvolvimento do pensamento e da linguagem, atividade de estudo, psicologia do jogo, periodização infantil e psicologia do adolescente. Para realizar suas investiga- ções o autor permaneceu fiel à Psicologia Histórico-Cultural tal como foi desenvolvida por Vigotski. Elkonin investigou o desenvolvimento infantil não de um ponto de vista naturalista, mas na relação dialética entre a criança e a sociedade ao seu redor, que são condicionados pela atividade, pelo ensino e pela educação, sempre mediados pelos adultos. Por fim, a autora apresenta de forma resumida a periodização do desenvolvimento desenvolvida por Elkonin.

Como fechamento da segunda parte da obra tem-se o texto "Construção de princípios para a organização do ensino na educação infantil a partir da análise da prática do professor: relato de um percurso investigativo pautado no materialismo histórico dialético", escrito por Juliana Campregher Pasqualini. A exposição aborda estudos teórico-conceituais sobre a relação entre desenvolvimento infantil e ensino na primeira infância e idade pré-escolar. A autora procurou investigar a educação infantil a partir da apreensão empírica da realidade escolar. Buscou superar a pseudoconcreticidade do fenômeno por meio de um processo de coleta, formação e participação do corpo educativo da escola. A autora concluiu que o professor deve dominar a lógica do desenvolvimento do psiquismo infantil, a lógica do conteúdo de ensino, conhecer o "estado atual das crianças", e organizar os conteúdos e os recursos para otimizar o processo de ensino-aprendizagem. Em suma, o professor deve levar em conta as peculiaridades psíquicas das crianças e utilizar-se dos recursos de ensino para que se potencialize a apropriação dos conteúdos e, assim, ocorra uma efetiva promoção do desenvolvimento psíquico da criança em idade pré-escolar.

A última parte do livro é intitulada "Em defesa de uma formação metodológica: exercitando a análise ou a análise em exercício?" inicia-se com o texto "Apresentação do grupo de estudos em Psicologia Histórico-Cultural (LAPSIHC-UEM): a importância do resgate de seus pressupostos teórico metodológicos" da autoria de Paulo Sérgio Pereira Ricci, Lenita Gama Gambaúva e Hilusca Alves Leite. O grupo de estudos orienta-se pelo materialismo histórico-dialético e tem como objetivo estudar a Psicologia Histórico-Cultural respeitando seu contexto de criação e seu método de pesquisa. $O$ texto discute a relação entre o contexto vivido pela União Soviética após a revolução e a criação de uma nova ciência psicológica pela Escola de Vigotski. Segundo os autores, a tarefa desta psicologia foi criar seus próprios princípios metodológicos e não simplesmente aplicar os pressupostos do materialismo histórico-dialético. Em suma, conhecemos um grupo comprometido com o estudo rigoroso dos fundamentos da Psicologia Histórico-Cultural, fato que evidencia a importância da formação para compreensão aprofundada desta teoria.

O texto que fecha o livro intitula-se "Aprendizagem e desenvolvimento na perspectiva da Psicologia Histórico-Cultural", elaborado por Elis Bertozzi Aita, Fernanda Santos de Castro, Jéssica Elise Echs Lucena e Silvana Calvo Tuleski. O capítulo é o resultado de estudos realizados pelo grupo apresentado anteriormente. A tese central do trabalho é evidenciar que o processo desenvolvimento humano não está dado de 
antemão, mas deve existir um processo de humanização através da internalização dos bens culturais e materiais. Aprendizagem é entendida por essa concepção como promotora de desenvolvimento. Porém, não é algo individual, mas sim intencionalmente realizado através do ensino. A educação escolar não é a única forma de promoção de desenvolvimento, mas seria a mais desenvolvida para tal função. Como conclusão as autoras apontam que a educação deve atuar na zona de desenvolvimento proximal com vistas a formar os conceitos científicos e, assim, desenvolver as funções psicológicas superiores dos alunos.

Discutir o papel das relações sociais de produção capitalista e seus impactos na formação humana é uma tarefa de grande importância, sobretudo em tempos de crise como atualmente vivenciamos. Isto porque alguns fenômenos ditos "psicológicos", tais como as patologias e os problemas de escolarização, por exemplo, passam a ser repensados a partir de um novo prisma, que não culpabiliza os sujeitos e procura suas fontes nos condicionantes sociais. Os autores desta coletânea se propuseram justamente lançar luz nessa relação e conseguiram exitosamente fomentar pensamento crítico nos campos da Psicologia e da Educação. Portanto, a coletânea é uma importante ferramenta para alunos e pesquisadores que buscam uma concepção teórica que rompa com a alienação produzida pelo discurso dominante e que se alinham aos interesses das classes subalternas e exploradas.

\section{Referências}

Vigotski, L. S. (2010). Quarta aula: a questão do meio na pedologia. Psicologia Usp, São Paulo, 21 (4), 681-701. 
